\title{
O ACASO NA LÍRICA DE RICARDO DOMENECK: FORÇAS DO ALHEIO, FIGURAÇÕES DO NÃO ALHEIO ${ }^{1}$
}

\author{
THE HAZARD IN RICARDO DOMENECK'S LYRICS: \\ OUT'S POWER, NOT-OUT'S FIGURATION
}

\author{
Elaine Cristina Cintra ${ }^{2}$ \\ UFU - Universidade Federal de Uberlândia (ILEEL) \\ USP - Universidade de São Paulo
}

\begin{abstract}
RESUMO: Na poesia de Ricardo Domeneck, o acaso é apresentado em nuances originais. Mais do que a afronta a uma razão já desdita, mais do que o desconhecido que ameaça a ordem estabelecida, nesta obra o acaso é o contingente possível no exercício de uma escrita estruturalmente projetada. A poesia, tal como o acaso, não virá somente de um resultado ou um consequente de uma ação, mas de um leque de probabilidades e acidentes que estão vinculados ao desejo, ao sujeito, ao tempo e à própria liberdade da forma. Assim, "o alheio e o não alheio" se tensionam, e o resultado é uma poesia de cortes bruscos, de dispersões na tentativa de representar o humano em seu tempo.
\end{abstract}

PALAVRAS-CHAVE: poesia contemporânea; acaso; Ricardo Domeneck.

ABSTRACT: In Ricardo Domeneck's poetry, the hazard is presented in some original gradations. More than an outrage to a questionable reason, more than the unknown that intimate the fixed order, in the work of this poet the hazard is the possible contingent in the exercise of a very projected writing. The poetry like the hazard, will not be created as a result only of the consequent of an action, but of some probabilities and accidents that are connected by the desire, the subject, the time and the own Form's. Therefore, the "out and not-out's" elements are tightened, resulting in a poetry with sudden cuts, dispersions, in the attempt of representing the human aspect in his present history.

KEYWORDS: contemporary poetry; hazard; Ricardo Domeneck.

Deriva-se à deriva

como se houvesse

sempre

algo ocorrendo

(DOMENECK, 2007, p.117).

\footnotetext{
${ }^{1}$ Este texto constitui uma reflexão parcial da pesquisa desenvolvida no Programa de Pós-Doutorado da FFLCH, Departamento de Teoria Literária e Literatura Comparada, USP, sob supervisão da professora Dr. ${ }^{a}$ Viviana Bosi.

${ }^{2}$ Doutora em Teoria Literária e professora adjunta do ILEEL/UFU. Email: elcintra@yahoo.com
} 


\section{Artimanhas do acaso}

O acaso está em todo lugar. Percorrendo tranquilamente as ruas das ciências exatas e biológicas, nas quais as leis da causalidade não mais sustentam os inadvertidos acontecimentos, ele permeia as páginas céticas do pensamento filosófico atual e ainda encontra seu viés nos lugares-comuns, palavras que rapidamente andam de boca a boca e ganham o status de verdade incontestável. A angústia impregnada pelo acaso no homem expõe-se em expressões como "a Deus dará", que aponta para uma aleatoriedade dos fatos, ou o provérbio "O acaso é pai dos grandes acontecimentos", no qual a grandeza somente ocorre na contramão do planejamento.

Sob formas pouco veladas, ele se veste de outros nomes, como sorte, coincidência, chance, destino ou acidente, ${ }^{3}$ provocando um significativo abalo no pensamento conduzido pela razão e encontrando força nas expressões artísticas que se conduziram pelos devires, como o surrealismo ou algumas propostas do concretismo.

$\mathrm{O}$ acaso define-se por ser tudo que acontece sem finalidade ou objetivo, ou sem ser resultado de um consequente, de uma continuidade e se apresenta como um acontecimento único, isento de relações, totalmente isolado em seu cerne. No acaso, os fenômenos ocorrem sem que seja possível a definição de seus movimentos determinantes. Na contramão do previsível, do predito, ele oblitera a ideia de que, por meio do entendimento de suas leis, é possível confiar no devir, confiscando toda segurança do estar no mundo.

Em sua aleatoriedade, então, pode-se dizer que o acaso se coloca como um acinte à razão, porque seu pressuposto propõe a falência da ideia de causalidade. A frase exageradamente repetida de Albert Einstein, "Deus não joga os dados"4 - que pode ser vista como um diálogo com o lance de dados de Mallarmé -, apresenta a crença cega nas causas e fins. ${ }^{5}$ Esta é uma posição que entende o universo como totalmente articulado em si, onde as ações se vinculam em uma unicidade orgânica, mesmo que, ainda, por nossa ignorância ou incapacidade, não a compreendamos.

No entanto nem sempre é este o entendimento possível das leis do universo. Mesmo com a afirmação de que os fenômenos são produtos de determinadas séries causais, pode ocorrer, como Ronaldo Entler (1997) afirma, o cruzamento de várias dessas séries com outras que lhe são totalmente independentes, o que leva a acontecimentos imprevisíveis, ou àquilo que podemos pensar como o acaso. Diferentemente da primeira posição, essa hipótese remete a uma outra compreensão do universo, onde a imprevisibilidade é sua lei maior.

Na Física, a aleatoriedade é um conceito no qual uma sequência de fenômenos não é determinada por nenhuma causa, ou seja, sem uma relação antecedente, o que Epicuro já antevia em seu conceito de "aleatoriedade objetiva". Tal fenômeno é imprevisível, e caso seja repetido, mesmo em situações idênticas, produzirá efeitos diversos que estarão submetidos ao azar. A imprevisibilidade do aleatório, discutida em uma ciência tão estrita como a Física, implica na desconstrução da ideia da infalibilidade do conhecimento científico e da construção cartesiana. $\mathrm{O}$ acaso vai além da razão.

\footnotetext{
3 “ $[\ldots .$.$] a complexidade do conceito de acaso já pode ser deduzida da quantidade de palavras que surgem em$ nosso cotidiano e que se relacionam ou se confundem com ele: sorte, azar, coincidência, acidente, contingência, indeterminação, destino, causa fortuita, aleatoriedade". (ENTLER, 1997).

${ }^{4}$ Conforme informação na Wikipédia, essa frase encontra-se em uma carta a Max Born, datada de 12 de dezembro de 1926.

${ }^{5}$ Em resposta a Einstein, o matemático Ian Stewart (1999) publica a obra Será que Deus joga dados? que propõe uma matemática na qual o determinismo e o acaso se encontram.
}

Disponível em: http://seer.fclar.unesp.br/casa 
Este nocaute à razão fica patente quando o acaso é vinculado ao caos, estudos que Ilya Prigogine, um químico ganhador do Prêmio Nobel, realizou. Para esse estudioso, os sistemas estáveis passam a ser a exceção de uma dinâmica na qual o tempo começa a ser visto como flutuante enquanto o caos torna-se parte de um sistema dinâmico instável. Na termodinâmica, este estremecimento do exato vai se ampliar com os estudos da entropia, grandeza que se associa a um "grau de desordem" e que se dá em sistemas isolados, ou seja, fugindo ao senso comum e às regras universais. Com tais estudos, as ciências exatas também acolhem a ideia do instável como uma de suas leis.

Ao suprimir as leis lógicas da razão, no homem à deriva dos acontecimentos, imerge um sentimento de impotência diante de seus devires, impossibilitando qualquer ação efetiva que possa situá-lo em uma posição ativa. É por esse prisma que Schopenhauer, em Aforismos para a sabedoria de vida, considera o acaso, concebendo-o como

[...] um poder maligno, no qual se deve confiar o menos possível. De todos os doadores, ele é o único que, ao dar, mostra ao mesmo tempo e com clareza que não temos direito nenhum aos seus bens, os quais devemos agradecer não ao nosso mérito, mas tão só à sua bondade e graça, que nos permitem até nutrir a esperança alegre de receber, no futuro e com humildade, muitos outros bens imerecidos. Eis o acaso: mestre da arte régia de tornar claro o quanto, em oposição ao seu favor e à sua graça, todo o mérito é impotente e sem valor. (SCHOPENHAEUR, 2002, p. 233).

Para esse filósofo, há três poderes no mundo: a inteligência, a força e a sorte, sendo que a última é a que mais atua nos acontecimentos da vida. Os esforços e empenhos do homem de pouca serventia são para a potência da sorte. $O$ curso da vida, então, não seria nossa obra, mas sim o produto de dois fatores: a série dos acontecimentos e nossas decisões, que interagem e se cruzam reciprocamente, alterando o plano inicial que por ventura tenhamos traçado. "O destino embaralha as cartas, e nós jogamos". (SCHOPENHAEUR, 2002, p. 234).

Este sentimento de impotência diante do inusitado dos acontecimentos apresenta uma visão trágica da vida humana, uma vez que o livre-arbítrio fica comprometido pela força dos acontecimentos. Tal visão é acentuada em uma obra de Clément Rosset (1989), A lógica do pior, na qual o autor desenvolve a tese de que o universo se constitui por um acaso absoluto. Assim toda situação estável não passaria de um momento provisório diante do caos primordial, incluindo, nessa lógica da exceção, o próprio homem. Dessa forma, na contramão de uma visão orgânica do mundo, na qual suas leis operacionais são determinadas e lógicas, o acaso seria a única verdadeira Lei que regeria um universo de caos, no qual os elementos que consideramos estáveis são, na verdade, acidentes e exceções.

A impossibilidade do conhecimento totalitário das leis do universo, a partir de uma visão de que o imprevisto pode sempre antevir, possibilita ao indivíduo uma liberdade diante das determinações lógicas. Assim, de uma certa forma, o acaso, que traz a possibilidade do desconhecido, liberta o homem da ditadura da razão, ao mostrar o quanto ela não é suficiente para elucidar a força do inexorável.

É esta a posição de Adorno e Horkheimer (1985) que, em sua Dialética do esclarecimento, ao contrapor os procedimentos deste e do mito, questionam a ideia de uma razão elucidativa, capaz de aclarar os mistérios e atenuar os medos que viriam do desconhecido. Para esses autores, esse conceito tão totalitário quanto qualquer outro sistema carrega inverdades que vão além das peculiaridades de seu método analítico, mas principalmente se consolidam na certeza de que "o processo está decidido de antemão" 
(ADORNO \& HORKHEIMER, 1985, p. 32). Pela identificação antecipatória do procedimento matemático, que Adorno e Horkheimer consideram o ritual do pensamento da época, e pela negação veemente do desconhecido, o esclarecimento acreditaria estar a salvo do temível retorno ao mito e, consequentemente, ao desconhecido.

Adorno e Horkheimer acreditam que o "horror mítico do esclarecimento" (p. 36) pelo mito, traz consequências graves ao indivíduo, afastando o sujeito, agora coisificado pela intrumentalização de sua subjetividade direcionada para o trabalho, das significações e plurivocidades do pensamento mítico, e submetendo-o inexoravelmente à razão totalitária:

O eu que, após o extermínio metódico de todos os vestígios naturais como algo de mitológico, não queria mais ser nem corpo, nem sangue, nem alma e nem mesmo um eu natural, constituiu, sublimado, num sujeito transcendental ou lógico, o ponto de referência da razão, a instância legisladora da ação. (ADORNO \& HORKHEIMER, 1985, p. 36).

Em sua visão de um sistema excludente, no qual a razão se coloca a serviço das forças de produção, Adorno apresenta, então, uma visão dialética na qual as questões fundamentais do pensamento ocidental estão sempre a se confrontar, sem, no entanto, chegarem a uma resolução.

Da mesma forma, é a partir de uma visão irresoluta que a literatura resgata a questão do acaso no presente, uma vez que, mesmo vertendo-se a sua força inexorável, o sujeito se inscreve através da tessitura de uma escrita. Assim, ao mesmo tempo que, em sua constituição, que pressupõe um projeto estético, a literatura arrebata do acaso sua indeterminação, ao escrever o homem e seu tempo, ela acaba por se verter ao encanto do inesperado.

Este texto pretende observar como um poeta do presente, Ricardo Domeneck, aborda a questão, considerando que o acaso torna-se, em sua poética, um dos temas mais recorrentes, refletindo-se na formalização de seus procedimentos estéticos e configurando alguns pressupostos de seu pensamento metalinguístico. É minha hipótese que este autor apresenta algumas nuances que dialogam com algumas inquietações teóricas atuais e que ele desenvolve, com algumas proposições originais, searas que vão além das manifestas na literatura de tempos anteriores.

Para isso, é necessário, antes, revisitar alguns momentos da literatura e de seus críticos, nos quais o acaso tornou-se preocupação de sua formulação, percorrendo alguns de seus desdobramentos na lírica moderna e contemporânea.

\section{O acaso e a literatura}

Não é de hoje que a literatura se volta para o acaso em sua representação do mundo, e, desde Homero, é possível pensar em devires que desafiam o livre-arbítrio do homem, empurrando-o aos caprichos do cosmo. Esses confrontos instauraram textos e figuras que situaram uma expressão ocidental do humano e sua relação consigo e com o mundo. Para Balzac, "o acaso é o maior romancista do mundo". 6

Por sua vez, as líricas modernas e contemporâneas abordaram o assunto ao trazer em suas tessituras poéticas algumas posições diante do desafio de expressar um sujeito

\footnotetext{
${ }^{6}$ Em francês: "Le hasard est le plus grand romancier du monde: pour être fécond, il n'ya qu'à l'étudier". (BALZAC, 1976, p. 21).
} 
à deriva de um tempo de imprevistos. Um dos exemplos mais marcantes se encontra em Baudelaire, no poema "A uma passante", no qual o imperativo da fugacidade de um tempo se dá no fulgor de um instante inesperado e contingente. ${ }^{7}$

Mas é em Mallarmé e seu lance de dados poéticos que as relações entre o acaso e a poesia se consolidaram na lírica moderna. Lutando contra o improviso, o poeta francês apostou no rigor construtivo, afirmando uma proposta poética de racionalidade e controle que teve seus seguidores leais, como Valéry e o nosso João Cabral. Obcecado pela ideia do Absoluto, o maior projeto de Mallarmé seria compor a Obra, com letra maiúscula, pretendendo, através da palavra absoluta, dominar o acaso. Ou como diz Ricardo Alfaia (2011):

[...] em busca do ômega, Mallarmé produz uma obra poética que, por trás do possível hermetismo, discute uma questão cara à filosofia de todos os tempos. Dentre todos os acasos de seu lance de dados, não deixa de ser notável fosse o poeta acertar o alvo do tema que hoje prepondera nos estudos mais avançados da Ciência: a discussão da possibilidade do Acaso como gênese do Universo.

Pode-se dizer que todo projeto estético de Mallarmé volta-se para o confronto entre o acaso e o absoluto da obra artística. Seus temas caros, como o nada, a página em branco, o silêncio, incorrem nessa discussão ao demonstrarem que o cultivo da consciência teórica e a elaboração extremamente racional da obra não levam a uma solução, mas remetem a uma pluralidade de posições que nem sempre se coadunam umas com as outras. Assim, a derrocada do intelecto se dá diante da impossibilidade de se prever todas as variações que o acaso apresenta na experiência de um processo artístico. O exercício extremo da linguagem acaba por levá-la a um esvaziamento e a um impasse: "tout hasard doit être banni de l'oeuvre moderne et n'y peut être que feint'. (MALLARMÉ, 1945, p. 230).

Este duelo com o acaso tem um momento privilegiado no poema mallarmeano "Un coup des dés", quando, ao prenunciar a falência do cálculo poético em detrimento às forças do acaso, Mallarmé termina por poetizá-lo, não somente ao pronunciá-lo como senhor dos processos, mas também ao inscrevê-lo no próprio exercício poético.

Nas vanguardas artísticas do século XX, a lírica coteja o acaso em diferentes propostas estéticas, tais como o surrealismo e o dadaísmo, ou na construção de expressões artísticas em novos suportes, como é o caso da proposta do blog "arteacaso" (2011), na qual o leitor/participante do site é convidado a elaborar frases aleatórias que virão a compor um poema:

Um conjunto de frases reunidas ao acaso pode compor um poema? E um poema como este será capaz de produzir sentido? É o que pretendemos descobrir. Os visitantes são convidados a deixar frases, que permanecem ocultas. Cada vez que o site acumula três frases, elas são publicadas na

\footnotetext{
7 O tema da fugacidade da beleza, relido em vários poetas modernos a partir de Baudelaire, é retomado pelo pessoano Álvaro de Campos em um poema que relaciona diretamente o tema ao acaso: "No acaso da rua o acaso da rapariga loira./ Mas não, não é aquela. // A outra era noutra rua, noutra cidade, e eu era outro. / Perco-me subitamente da visão imediata, / Estou outra vez na outra cidade, na outra rua, /E a outra rapariga passa. // Que grande vantagem o recordar intransigentemente! / Agora tenho pena de nunca mais ter visto a outra rapariga, / E tenho pena de afinal nem sequer ter olhado para esta. / / Que grande vantagem trazer a alma virada do avesso! / Ao menos escrevem-se versos. / Escrevem-se versos, passa-se por doido, e depois por gênio, se calhar, / Se calhar, ou até sem calhar, / Maravilha das celebridades! [...]”. (PESSOA, 1992. p. 376).
} 
forma de um pequeno poema, sem que um "coautor" conheça a contribuição do outro. Veja os resultados e participe! (http://www.iconica.com.br/arteacaso/poemas.html).

Tal experiência, que iguala o poder criativo do autor ao do leitor, desmitificando a figura premente autoral e deslocando toda a autoridade do processo literário para o próprio texto, coloca o sujeito, figura que centraliza a lírica, como elemento aleatório na produção poética. Se o próprio produtor do texto é aleatório, como pensar, então, em uma expressão do eu quando tantos eus estão ali inscritos? Teria a lírica se tornado apenas o espaço de experimentações linguísticas que se potencializam diante de novos recursos tecnológicos? Ou poderia se pensar no surgimento, diante da fragilidade da figura do indivíduo nestes tempos de tribo, se formos acompanhar a leitura da contemporaneidade realizada por Maffesoli (1998), em uma lírica "coletiva"? Assim, a iniciativa de compor um poema que se faz ao acaso de seus autores implica, mais do que dessacralizar a figura autoral, imprimir a marca de um desconforto da voz individual, fragilizada pelos ditames de um tempo no qual o sujeito se dilui em função de outras mitificações, como a tecnologia ou mesmo a ideia de quantidade.

O acaso na literatura, e em geral na arte, é sempre um elemento que surge, de alguma ou várias formas, para evidenciar um desconforto do mundo, ou seja, ele faz vislumbrar um elemento de resistência. No surrealismo, o acaso remete à ideia de uma insuficiência do mundo. Através do hasard objectif (acaso objetivo), o surrealismo propunha registrar o extraordinário, o que, para Peter Bürger, "se trata de dominar o acaso, tornar repetível o extraordinário". (2008, p. 135). Com a atenção voltada ao que foge à racionalidade e à ordenação do mundo burguês, o surrealismo apresenta, no acaso, uma face de resistência, uma vez que, "ao indivíduo que protesta contra a sociedade não resta senão abandonar-se a uma experiência com característica e valor que consistem na falta de compromisso para com estes fins". (BÜRGER, 2008, p. 135). Assim, deixar-se fluir pela aleatoriedade seria uma maneira de não acreditar em propósitos e razões, opondo-se à ordem estabelecida.

A leitura de Bürger dessa época estabelece uma distinção entre produção direta e produção indireta do acaso. Se a produção indireta se dá no registro do acaso, a produção direta é verificada em alguns movimentos da pintura dos anos 1950 tais como o "tachismo", o "action painting" e outros, nos quais a intenção é substituída pela espontaneidade. Nesse tipo de obra de arte, o cálculo encontra-se nos meios, e o resultado, por seu lado, é imprevisível.

Na poesia, a produção direta do acaso, ou seja, o acaso como princípio de construção, é mais exemplarmente observada nas manifestações que estabelecem um crivo no concretismo, estética que fomenta um pacto com o princípio da aleatoriedade em seu jogo criativo. Apesar de todo cálculo, a poesia concreta remete a alguns dispositivos do jogo, tal como a repetição no novo, na qual o resultado é sempre imprevisível. Vale, no entanto, ressaltar que neste jogo estético é preciso ver além da excessiva experimentação verbovocovisual. Bürger afirma que as construções que se deixam levar pelo jogo do acaso indicam o estremecimento do individualismo burguês e um exercício de liberdade da razão dominante $^{8}$.

\footnotetext{
${ }^{8}$ Vale verificar em Bürger, a citação de Köhler a respeito: “O devotamento entusiástico ao material e sua resistência, produtora de acasos, desde os poemas de pedaços de papel de Tristan Tzara até o mais moderno dos hapenings, não é causa, mas consequência de um estado da sociedade, na qual tão somente o que se manifesta por meio do acaso é poupado da falsa consciência, livre de ideologia, não estigmatizado pela total reificação das condições humanas de vida”. ( KÖHLER apud BÜRGER, 2008, p. 132).
} 
A respeito da produção indireta, pode-se vislumbrar o acaso em vários momentos da lírica do século XX. Um dos poetas que mais problematizou o tema foi Leminski, autor cuja influência de Mallarmé é significativa e que, em sua obra, trava um embate com o acaso no qual ficam claros os confrontos que o sujeito estabelece entre seus desejos e as flutuações do tempo:

\author{
atrasos do acaso \\ cuidados \\ que não quero mais \\ o que era pra vir \\ veio tarde \\ e essa tarde não sabe \\ do que o acaso é capaz (LEMINSKI, 2004, p. 28).
}

Herdeiro dos poetas concretos, com quem mantinha uma íntima relação, Leminski deixa entrever, na mobilidade dos versos, a dança da aleatoriedade, figurando um sujeito e uma palavra à deriva do acaso. O forte sentimento de insatisfação, causado pelo desencontro entre o desejo do indivíduo e o tempo do acontecimento, é representativo da impotência deste ser. Assim, as palavras "atrasos" (em uma homofonia com a palavra "acaso", levando a uma identificação entre os dois vocábulos), "tarde" (que se repete na segunda estrofe por duas vezes, na primeira como adjetivo e na segunda como substantivo) remetem a uma temporalidade que não coincide com o desejo do homem, o que gera incertezas e insatisfações. O homem estaria, então, sob o domínio de uma ingerência que ignora seus apelos e que fulmina suas possibilidades de felicidade.

Também esta posição de impotência é registrada em vários poetas contemporâneos, como Iacyr Anderson Freitas que, em seu livro Viavária, apresenta a força dissipativa do acaso: "Por isso urge unir, a frio, o que o acaso/dissipou [...]". (FREITAS, 2010, p. 17). Na poesia de Ricardo Domeneck, porém, este assunto vai se tornar o centro da discussão de um de seus livros.

\title{
3. Contingências do acaso em Ricardo Domeneck
}

Ricardo Domeneck atualiza essa discussão, uma vez que situa o acaso em uma posição igualitária com a vontade e o desejo do sujeito, realizando, assim, um duelo tenso e contínuo que se reflete na forma oblíqua, em que os cortes nos versos e as ambiguidades bruscas remetem à resposta da poesia aos termos impostos pelos tempos.

Em sua obra, Domeneck apresenta um tempo de desconstituições e inanições. O presente, em suas diferentes matizes, é promíscuo e inabordável, e o sujeito se defronta com uma busca irrefreável pelo nome: "sempre digo ao/telefone meu/nome querendo/dizer sou eu/como quem/diz estou/chegando" (DOMENECK, 2007, p. 7). Assim, em vários momentos, a ação maior do sujeito na poesia desse autor, centra-se na necessidade de definir os nomes e de inscrevê-los na ação da escrita, de torná-los "próprios". Mas os nomes, tão aleatórios como tudo mais que se rege pelo acaso, esvaem-se: "ninguém nome/ninguém" (DOMENECK, 2007, p. 37), e o exercício de identidade imposto pela escrita torna-se tão contingente quanto os fatos que o cerceiam.

De maneira geral, a poesia de Domeneck desconforta. Através do exercício exaustivo dos enjambements e das elipses que compõem um ritmo quebrado e impactante, 
emoldurado pela invasão de inúmeros estrangeirismos, seus poemas vêm marcados por uma dicção agressiva que propõe uma reflexão sobre um tempo de negatividades.

Em Carta aos anfíbios, publicado em 2005, a ideia de acaso aparece junto às secreções, líquidos, levezas e levitações, imagens que se tensionam com outras nas quais a dureza de um chão estreito evidencia a realidade. Mas é no livro de Domeneck publicado em 2007, a cadela sem Logos, que o tema é redimensionado de maneira mais ampla e sistematizada. Se no primeiro livro, o acaso aparecia como uma das possíveis imagens, em $a$ cadela ele se torna elemento essencial na construção da tensão poética, o que será possível verificar em vários paralelismos, como o acaso e o desejo, a realidade e o sujeito, o nome e o eu (ou ninguém).

Este livro está centrado na (in)definição de um sujeito que não pode se dar a conhecer por si só - ele é o dentro e o fora: "Tudo o que é humano é alheio e não alheio" (DOMENECK, 2007, p. 117). É neste sentido que o acaso e seus desdobramentos (sorte, aleatoriedade, chance etc.) surgem como um dos elementos externos que, de forma contundente, agem sobre este ser:

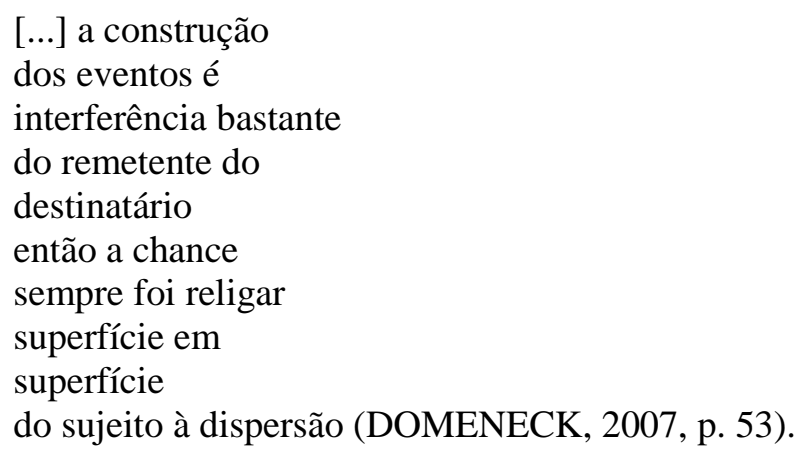

Tanto sujeito quanto mundo, em Domeneck, não se dão por si só, mas conjugam-se em suas vontades, em suas tensões e suas contiguidades. A vontade do mundo, no entanto, é aleatória, não se origina nos pressupostos de uma razão idônea e irrefutável, mas no desconhecido, que tanto pode favorecer como desfavorecer. As "interferências" são, nesse tempo, incontáveis, e as chances se multiplicam vertiginosamente. E é com essa multiplicidade que o indivíduo tem que operacionalizar:

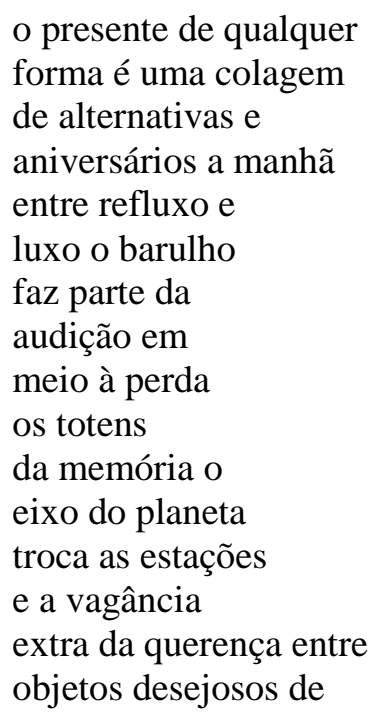




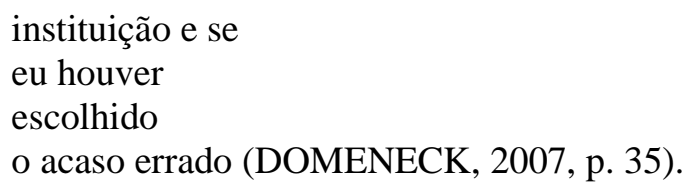

As definições do presente que este poema oferece coadunam com as visões de vários intérpretes do século. Tempo de mercantilização, variedades e multiplicidades, é também um tempo de falta, fato registrado em algumas nuances da lírica atual. Este excesso/esvaziamento leva o homem do presente a uma necessidade constante de se cercar de informações, "pré-encher-se" dos acontecimentos da atualidade, com a midiatização garantindo-lhe rapidez e inserção em um mundo digital que oferece as mais variadas possibilidades de acesso.

O fluxo dos tempos e dos acontecimentos, uma das marcas do acaso nas abordagens realizadas em Carta aos anfíbios, aqui se transforma em "refluxo e luxo". O refluxo, movimento que se opõe a outro, ou, em outra acepção, o retrocesso, metaforiza este momento de contradições, de idas e vindas que não se resolvem; e o luxo aponta para os excessos deste tempo. Mesmo o acaso é visto pelo sujeito, ironicamente, como uma das possibilidades das escolhas, fragilizando a ideia mítica de que ele reinaria soberano sobre os eventos do homem.

Entretanto o poema aponta especialmente sobre o desejo em face aos acontecimentos. Como conciliar tanto desejo a um tempo, mesmo aparentemente tão variado, tão anêmico? A tensão estende-se ao máximo, e o desejo torna-se, neste autor, o centro gravitacional do acaso. Surge assim, em um movimento oposto ao anterior, um desejo do acaso, do contingente, para que a surpresa venha trazer algo que supostamente não vai se dar no curso natural:

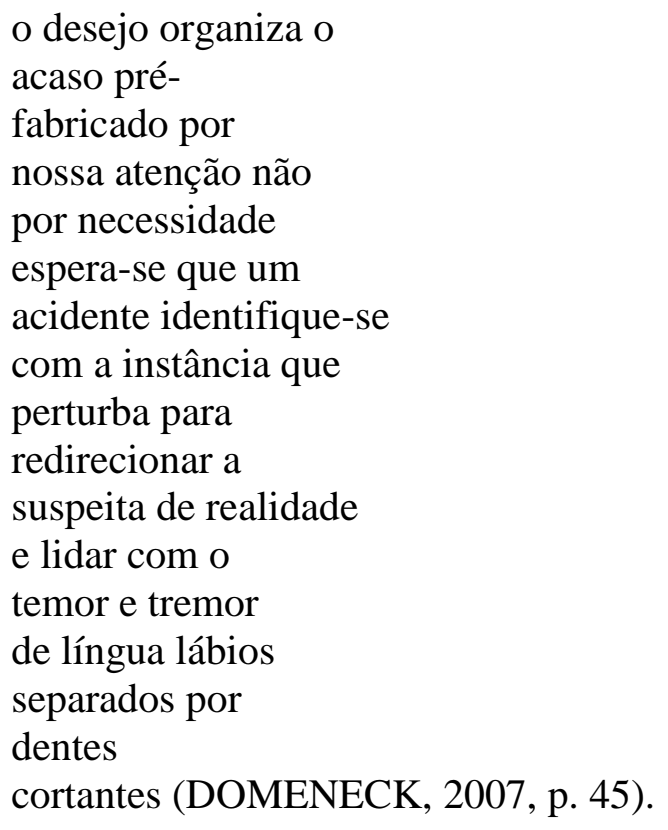

O acidental precisa, então, coincidir com o desejo, elemento significativo da subjetividade e a expressão do eu em seu mais congênito aspecto, para que a realidade seja redimensionada. $\mathrm{O}$ intercâmbio é profícuo: o acaso não mais se apossa de toda a história do sujeito, mas é também por seu desejo redirecionado. À deriva, o homem se coloca entre as 
duas forças, uma alheia e outra não alheia, e o resultado disso é a sua ressignificação, ou um texto poético inscrito em sua própria dispersão.

A memória trava também com o acaso uma luta ímpar, apresentando facetas caleidoscópicas. O acaso e a memória se confrontam, aliam-se em dimensões diversas, estabelecem pactos sutis e mostram que os tempos se tencionam também nestes movimentos do alheio e do não alheio.

Em vários momentos desta poética, a memória surge como par antitético do acaso:

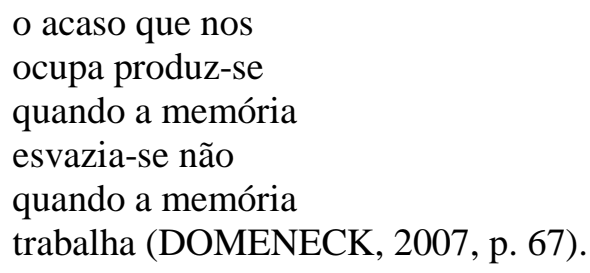

Mas, se sem a memória estamos à deriva do esquecimento, é pertinente ver o outro lado da questão, esquecer pode ser um ato aleatório, nem sempre por decisão ou necessidade, apenas como resultado das contingências do mundo: "se esquece muito/no mundo/por escolha por/precisão por acaso". (DOMENECK, 2007, p. 85).

Também não é somente a memória vivida que a poesia de Domeneck evoca ao entrelaçá-la com as facticidades do acaso. A memória do "não/acontecido", daquilo que pode não ter sido ou que mesmo se foi está em processo de negação, ou seja, a memória que reelabora as lembranças e as nomeia remetendo-lhes novas significações, ou que cria novas poeticamente, necessita do acaso para a sua "manutenção do projeto":

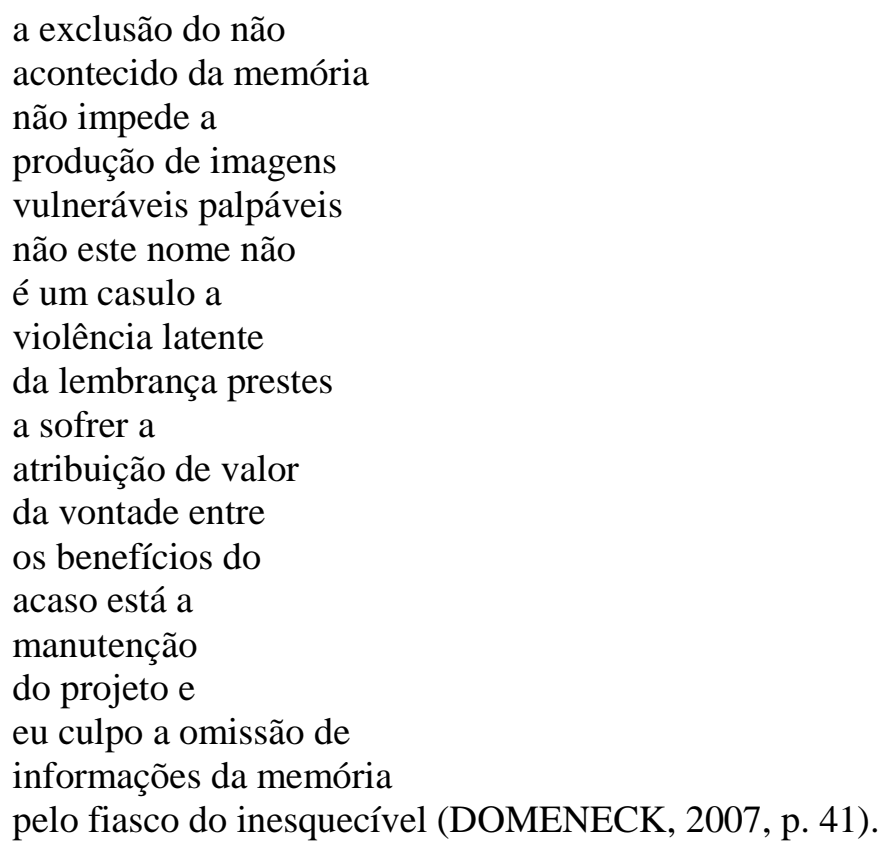

No poema cujo tom é de negação e culpa, o acaso surge como aliado ao processo de lembrar mas também ao de esquecer, desviando a atenção, remetendo a outras instâncias, mediando a dolorosa perpetuação de alguns tempos. Escrever é estar à deriva do que se lembra e do que se esquece, e esta escrita-acaso traz ambas as possibilidades. 
O acaso então, em Ricardo Domeneck, acaba por se tornar um evento significativo também no ato da escrita, levando-o a algumas constatações metalinguísticas, que propõe as escolhas como importantes na criação, mas também a aleatoriedade como toante no resultado:

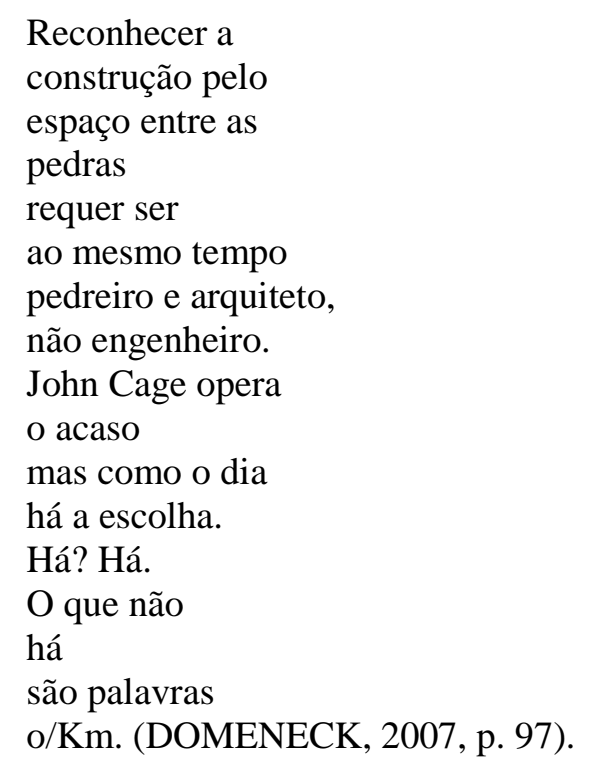

Se, como é dito em outro poema, o local da queda das folhas é escolhido com antecedência, o vento, metáfora do contingente que aparece com frequência em Carta aos anfíbios, pode levar essa escrita-folha para margens imprevistas: "O resultado dos dados/já está contido/no movimento dos punhos/ Mas há o vento, é/considerável?/ Ele precipita a mudança/ algo não equacionável [...]”. (DOMENECK, 2007, p. 87-88). Assim, Mallarmé, sombra inescrutável de Domeneck, ainda dá a palavra final, mostrando que mesmo a razão poética também está submetida aos desmandos do acaso. No entanto, em Domeneck, os artifícios do acaso intercambiam-se com a inesgotável potência do desejo do sujeito, em um conflito que não se resolve, mas que se faz inscrever na bela tensão de uma poesia inquieta e dissonante.

Faces variadas do acaso se dão, então, na poesia de Ricardo Domeneck: se o acaso ainda é fonte da imobilidade do homem diante dos eventos ( "O acaso atesta o deliberado/ E perdemos dias preciosos") (DOMENECK, 2007, p. 99), ele também faculta possibilidades que o engessamento do sistema não permite: "[...] segue o/intercâmbio entre/interno e externo/da nutrição da/chance do/acaso crescem/o nome o júbilo." (DOMENECK, 2007, p.18).

Nos revides entre o alheio e o não alheio, as probabilidades propagam-se, e o dia pode apresentar mais do que a previsível rotina. A potencialização das chances e possíveis acidentes, amplia as vivências e, por conseguinte, as escritas dessas vivências. Da mesma forma, sujeito e acaso enfim se conciliam, mesmo que de maneira irônica: "meus erros/sistemáticos meus/erros ao acaso são/iguais". (DOMENECK, 2007, p. 82).

O acaso apresenta, deste modo, gradações originais na poesia de Ricardo Domeneck. Mais do que a afronta a uma razão já desdita, mais do que o desconhecido que ameaça a ordem estabelecida, em sua poesia o acaso é o contingente possível no exercício de uma escrita estruturalmente projetada. A poesia, tal como o acaso, não virá somente de um 
resultado ou um consequente de uma ação, mas de um leque de probabilidades e acidentes que estão vinculados ao desejo, ao sujeito, ao tempo e à própria liberdade da forma.

Não mais o acaso é visto como isento de relações, e isolado em sua soberania. Em Domeneck o acaso se verte ao desejo e o desejo se deixa levar pelo acaso. Desejar é, de certo modo, colocar-se à deriva. O presente, portanto, acaba por se tornar o tempo do desejo, e a poesia deste autor pronuncia-se como a escrita deste desejo.

\section{REFERÊNCIAS}

ADORNO, T. HORKHEIMER, M. Dialética do esclarecimento: fragmentos filosóficos. Tradução Guido Antônio de Almeida. Rio de Janeiro: Jorge Zahar, 1985. 223 p.

ALFAIA, R. Dados soltos num jogo de dardos. Disponível em: $<$ http://www.blocosonline.com.br/literatura/prosa/artigos/art034.htm>. Acesso em: 10 jul. 2011.

ARTEACASO (blog). In: $<$ http://www.iconica.com.br/arteacaso/poemas.html $>$. Acesso em: 18 maio 2011.

BALZAC. Etudes de moeurs: Scènes de la Vie Privée. Tome1. Paris:Pléiades, 1976, 1567 p. BÜRGER, P. Teoria da vanguarda. Tradução José Pedro Antunes. São Paulo: Cosac Naify, 2008. 272 p.

DOMENECK, R. A cadela sem Logos. São Paulo: Cosac Naify; Rio de Janeiro: 7Letras, 2007. 144 p. (Coleção Às de colete; 16.)

Carta aos anfíbios. Rio de Janeiro: Bem-Te-Vi, 2005. 108 p. (Canto do Bem-Te-Vi).

ENTLER, R. Arte e acaso: introdução ao problema. In: ICONICA. Disponível em:

<http://www.iconica.com.br/arteacaso/artigos/ronaldo_entler_arte.html >. Acesso em: $02 \mathrm{dez}$. 1997.

FREITAS, I. A. Viavária. São Paulo: Nankin; Juiz de Fora MG: Funalfa, 2010. 136 p.

LEMINSKI, P. La vie em close. São Paulo: Brasiliense, 2004. 184 p.

MAFFESOLI, M. O tempo das tribos. O declínio do individualismo nas sociedades de massa. Trad. Maria de L. Menezes. 2.ed. Rio de Janeiro: Forense Universitária, 1998. 232 p.

MALLARMÉ, Ouevres complètes. Paris: Gallimard; Pléiade, 1945. 1659 p.

PESSOA, Fernando. Obra poética. Rio de Janeiro: Nova Aguilar, 1992. 845 p.

ROSSET, Clément. A lógica do pior. Rio de Janeiro: Espaço e tempo, 1989. 198p.

SCHOPENHAUER, A. Aforismos para a sabedoria de vida. Tradução, prefácio e notas Jair Barboza. São Paulo: Martins Fontes, 2002. (Clássicos). 297 p.

STEWART, Ian. Será que Deus joga dados? A nova matemática do caos. São Paulo: Jorge Zagar, 1999. $336 \mathrm{p}$.

Recebido em: 15.07 .11

Aprovado em: 12.09.11 